\title{
Médicas de la Facultad de Medicina de Cádiz, último tercio del siglo XIX y siete primeras décadas del siglo XX
}

\author{
Beatriz Sainz Vera \\ Doctora en Medicina. Especialista en Medicina Interna y Neumología. \\ e-mail: bsainzvera@yahoo.es
}

RESUMEN: Se investiga sobre las primeras médicas de la Facultad de Medicina de Cádiz en el último tercio del siglo XIX y primeros 70 años del siglo XX, desde el inicio de la carrera y licenciatura, doctorado y especialidad si constan en sus expedientes, así como la consideración profesional por la sociedad y los colegas masculinos hacia ellas en dichos períodos. Revisamos al inicio del trabajo el papel de la mujer en la profesión sanitaria a lo largo de la historia.

Palabras claves: Médicas, Facultad de Medicina de Cádiz, Siglos XIX-XX.

\section{Women physicians in the School of Medicine of Cadiz the last third of XIX century to the 70's of XX}

ABSTRACT: The investigation is over the first women physicians in the School of Medicine of Cádiz, from the last third of XIX century to the 70, s of XX, from the beginning of their university studies, degrees, doctorates and specialties if that information appears on their files, as well as the review about the professional consideration of their male colleagues and society in the age. So, we summarize the history of the sanitary women.

Keywords: Women physicians, School of Medicine of Cádiz, XIX-XX centuries.

\section{Real Academia de la Lengua Española: MÉDICA}

En 1986 la RAE acordó que no debe emplearse el masculino para referirse a una mujer como es el caso de la médico. «En los sustantivos de profesión que cuentan con una forma para cada género, debe emplearse obligatoriamente el femenino cuando el referente es la mujer, si se trata de una mujer debe usarse la expresión médica».

El 31 de enero de 2019 la RAE recordó el uso de la palabra médica para referirse a una mujer que esté legalmente autorizada para ejercer la medicina. 


\section{LA MUJER SANITARIA A LO LARGO DE LA HISTORIA}

Durante siglos, el mundo de la ciencia estuvo vetado para las mujeres. En las distintas sociedades primitivas ha existido una «medicina popular»y en muchas de ellas eran las mujeres de edad las que elaboraban y aplicaban remedios. En este período pretécnico, la medicina se basaba en el empirismo y la magia. En el mundo antiguo, durante el período helenístico, acudían algunas mujeres a las escuelas de medicina, practicando sobre todo ginecología. Sorano de Éfeso, discípulo de Asclepíades, escribe un libro de obstetricia y ginecología dirigido a estudiantes mujeres porque «las mujeres tienen una forma distinta de enfermar y deben ser tratadas por mujeres». En varios escritos romanos, por ejemplo, en el Libro de Scribonius Largus, se citan mujeres que estudiaron medicina con algún maestro, la mayoría familiares de hombres influyentes, pero su ejercicio no era público, sino que se reducía al ámbito familiar.

Galeno (131-201 d. C.) será el referente de su época y otras posteriores hasta los tiempos modernos. Describió el aparato genital femenino, mantuvo la teoría de la mayor frialdad femenina, basada precisamente en sus órganos imperfectos frente a la perfección de los del varón.

Ya en la Edad Media, en el mundo árabe, existieron algunas escuelas de medicina destinadas a mujeres desde oriente a occidente. En las cultas ciudades de Córdoba y Toledo se impartían clases destinadas a mujeres dirigidas a la enseñanza de cuidados obstétricos, ginecológicos y de los niños, porque eran ellas las únicas que podían atender al harem. En la alta Edad Media, destaca Hilda de Whithy (614-680), abadesa en un monasterio, que desarrolló una importante labor intelectual, enseñaba entre otras disciplinas medicina y atendía a los enfermos. La profesora y médica Trótula (Escuela de Salerno, siglo XI) escribió dos libros, De Compositione Medicamentorum y De Mulierum Passionibus, éste último sobre cuidados ginecológicos y del neonato.

Cuando surgen las universidades en el siglo XIII, las mujeres no pueden acudir. Ellas ejercen como comadronas, que no es una disciplina universitaria. En el siglo XIV Sarah St. Gilles dirigió una escuela de medicina en Montpellier (Bernis Carro y Cámara González 1982) $)^{1}$.

Durante los siglos XV y XVI, se persigue la brujería, y entre los perseguidos y quemados la mayoría fueron mujeres pobres, solas y sin instrucción. Muchas de ellas eran herboristas, prescribían bebedizos y jarabes elaborados por ellas mismas o ejercían de parteras. Sobre ellas cayó la persecución, la infamia y el aislamiento. Las religiones y el afán de anular la medicina no científica estuvieron detrás de este hostigamiento.

Hasta el siglo XIX continuaron barberos, sanadoras y parteras atendiendo a la mayoría de la población. Los médicos oficiales, titulados universitarios, atendían a los cortesanos y burgueses. Las mujeres se ocupaban de cuidar la salud en el ámbito doméstico. Su condición femenina y el ocultismo que rodeaba lo relacionado con la toco-ginecología les obligó a

\footnotetext{
${ }^{1}$ En el libro Liberación y utopía, edición de $\mathrm{M}^{\mathrm{a}}$ Ángeles Durán, escriben entre otras autoras, las médicas Carmen Bernis y Cristina Cámara (capítulo X) sobre «La mujer y la Medicina», realizando un recorrido histórico pormenorizado de la participación de la mujer en la constitución histórica de la medicina.
} 
adquirir conocimientos en medicina natural, empleando plantas y bebedizos acompañados a veces de rezos y ritos para ir solventando problemas de salud sencillos en las familias, transmitiéndose de madres a hijas.

La mujer ha tenido a lo largo de la historia un papel destacado, pero escondido en el mundo de la medicina hasta fechas recientes. Las tareas que habitualmente desempeñaban las mujeres relacionadas con la medicina estaban centradas en tres actividades básicas que se reducían a la atención de todo lo relacionado con el embarazo y parto, el cuidado de los niños y como «asistentes del médico». Esto es, comadronas y enfermeras, siendo ambas casi exclusivamente realizadas por mujeres.

Es la de enfermera la profesión sanitaria más relacionada con la mujer, realizando una importante labor en los hospitales. Había mujeres con necesidades económicas, voluntarias, viudas con hijos a su cargo y sin recursos, que cuidaban de las enfermas y realizaban además tareas de limpieza y en ocasiones se les asignaba una dotación económica si demostraban que carecían de medios y que guardaban el «voto de castidad viudal» (Corpas Mauleón 1994).

Las dificultades para el acceso a la enseñanza superior, las consideraciones sociales y económicas, derivaron a las estudiantes hacia las escuelas de enfermeras laicas. Así a finales del XIX (1896) se funda en Madrid la Escuela Santa Isabel de Hungría por Federico Rubio y Galí, la primera escuela de enfermería laica en España que se crea siguiendo los parámetros de los centros más innovadores europeos, pero adaptándolos a la mentalidad y desarrollo de la España de finales del XIX (Eseverri Chaverri 1984).

En Europa fue muy importante la figura de la inglesa Florence Nightingale, considerada la precursora de la enfermería profesional moderna. Nace en Florencia (Italia) en 1820 y fallece en Londres (Gran Bretaña) en 1910. Fue enfermera, escritora y estadística. Funda en 1860 en el Saint Thomas Hospital de Londres la Escuela de Enfermería, siendo la primera escuela laica de enfermería del mundo. Alcanzó fama mundial por sus trabajos en la asistencia a heridos en la guerra de Crimea y contribuyó con sus ideas a fomentar el feminismo inglés. En 1860 expuso sus pensamientos en una edición privada de Suggestions for thought to the searchers after religious truth. En el año 2008, la Wilfrid Laurier University de Canadá publica la obra de Nightingale: The collected works of Florence Nightingale (McDonald 2008).

La labor asistencial ha estado también muy ligada a algunas órdenes religiosas femeninas. En España, la pionera fue la Madre María Rafols Bruna. En 1803 realizó la ardua tarea de cuidar a los enfermos de la epidemia de peste que se produjo en Barcelona. Fundadora de Las Hermanas de la Caridad de Santa Ana en el Hospital de Nuestra Señora de Gracia de Zaragoza en 1807. Llegó incluso a examinarse de Flebotomía ante la Junta del Hospital para poder realizar sangrías, que como sabemos constituía una práctica médica habitual y supuestamente curativa para muchas dolencias en esa época. Fue beatificada (Sanz Artibucilla 1970).

Desde el siglo XIII que se constituyeron los estudios de Medicina en Europa, las universidades dictaron la norma de prohibir el acceso de las mujeres a esta disciplina y asî permaneció más de 500 años, aunque hubo algunas excepciones en Alemania e Italia. De hecho, parece que la primera mujer titulada en Medicina fue en el XVIII la alemana Dorotea 
Leporin Erxleben, que pudo estudiar por habérsele concedido un permiso real (Ortiz Gómez 1985-1986) $)^{2}$.

Durante el siglo XIX, la mujer se incorpora poco a poco a los estudios de Medicina en Europa. Fueron inglesas las primeras licenciadas que ejercieron la profesión en dicho siglo. Destacó la primera, Elizabeth Blackwell (1821-1910) inglesa de nacimiento que emigró a los Estados Unidos donde ejerció la profesión, acabando sus días en Inglaterra, jubilándose como catedrática de Ginecología.

En España, la incorporación de las mujeres a la carrera de Medicina se produjo en las dos últimas décadas del siglo XIX, en un número muy escaso pero con gran repercusión social, se polemizó sobre si eran o no aptas para estudiar y ejercer medicina (Álvarez Ricart 1969; Flecha García 1996).

Durante esa época en nuestro país el número de médicas era menor que en países vecinos europeos. Probablemente los motivos fueron varios: la consideración social, tan sexista para que ellas accedieran a la ciencia y conocimientos, la educación recibida, sin olvidar lo económico, y la tradición religiosa. En un país como el nuestro, eminentemente católico, la jerarquía eclesiástica ha tenido siempre mucho poder, para ellos la mujer era el sostén de la familia, papel de vital importancia, trascendental, y al que debían dedicarse en cuerpo y alma, pero que impedía en muchos casos el crecimiento intelectual y la formación académica. La mujer que trabajaba era por imperativo económico, justificándose así el trabajo no cualificado de las mujeres de clase obrera. El de tipo intelectual, se reservaba para las clases media y alta pudientes y que habían recibido alguna formación. La medicina no era muy bien considerada como carrera a realizar por la mujer en defensa del pudor.

La universidad como servicio público data del siglo XVIII, consolidándose como tal en el último tercio del XIX. Cuando el sistema educativo accedió a que las mujeres recibieran formación académica era manifiestamente distinta a la de los varones, se establecieron medidas diferenciadoras y se pusieron trabas al acceso a las enseñanzas media y superior. El Real Decreto de 21 de octubre de 1868 reguló la libertad de enseñanza y comenzaron las primeras mujeres a solicitar permisos para iniciar educación secundaria en los institutos o acceder a los exámenes por libre. Entre los años 1871 y 1872, las primeras andaluzas solicitan estos derechos, una de Huelva y otra de Cádiz.

Posteriormente, en 1882 aparece una Real Orden de 19 de marzo en la que se da marcha atrás y se prohíbe que las mujeres accedan a la universidad y un poco más tarde también a los institutos. Entre los años 1888 y 1910, una nueva legislación permite de nuevo el acceso, pero se exigían permisos especiales como requisito indispensable para que la mujer accediera a la universidad, entre ellos el permiso del Rector y del propio centro escolar.

A partir de 1873 comenzaron ciertas universidades en España a contar con mujeres entre sus estudiantes, en este orden fueron las primeras: Barcelona, Valencia, Valladolid, la Universidad Central de Madrid, Salamanca, Sevilla, Granada, Santiago y Zaragoza.

${ }^{2}$ Comentario citado por la autora de una referencia en su bibliografía: CHAFF, S. L., et al. 1977. Women in Medicine. A bibliography of the literature on women physicians. London: Scarecrow Press, 1977. pp. 1-37.

DOI del artículo:

https://doi.org/10.25267/Cuad investig fondos arch UCA.2021.i3.05 
Previamente María Elena Maseras Ribera solicitó al Rey Amadeo de Saboya que le permitiese cursar estudios de bachillerato primero y posteriormente en la Facultad Mayor, concediéndoselo, promulgando poco tiempo después una Real Orden ( 2 de septiembre de 1871) que la autorizaba a realizar estudios en la segunda enseñanza. En el curso 1872-73 se matricula en la Universidad de Barcelona en varias asignaturas de la carrera de Medicina, siendo la primera mujer matriculada en esa universidad y la primera médica titulada en 1879. (Flecha García 1996) ${ }^{3}$.

Dos años después, se matriculaba en la misma Universidad de Barcelona Dolores Aleu Riera de varias asignaturas de la carrera de Medicina, licenciándose en 1880. Matriculadas en régimen de enseñanza oficial, no acudían a clases por miedo a que los condicionamientos sociales de la época, por ser mujer, causara algún impedimento, aunque no estaba prohibido.

En 1877 se matriculan dos nuevas alumnas en la Universidad de Barcelona en su facultad de Medicina: Martina Castell Ballespí, licenciada en 1881 (primera Doctora en Medicina), e Isabel de Andrés Hernández. En 1878 se matricula en la Facultad de Medicina de la Universidad de Valladolid Elia Pérez Alonso. Poco después, en 1885 acaba Adoración García Aranda en la facultad de Medicina de Madrid. Al año siguiente otras terminan en las Facultades de Barcelona (1), Valladolid (1) y Valencia (2), no conociéndose nuevas licenciadas hasta 1896 que termina la carrera la gaditana Antonia Monreal y Andrés, primera médica de la Facultad de medicina de Cádiz y primera universitaria andaluza, que inició la carrera el curso $1889-90^{4}$.

Así mismo, la alumna cubana María Asunción Menéndez de Luarca Díaz, farmacéutica previamente por la Universidad de la Habana, obtuvo posteriormente (1893) el título de Medicina en la Universidad norteamericana de Atlanta, siéndole convalidado y licenciándose en Cádiz en $1894^{5}$.

En la Facultad de Medicina de Cádiz se matriculó en 1911 María del Mar Terrones Villanueva concluyendo la carrera en $1915^{6}$, fue por ello la primera médica del siglo XX en Andalucía y posteriormente Francisca Medina Verdeja licenciada en 1918. Eudoxia Pirix en la Facultad de Granada, licenciada en 1920, fue la primera médica que se colegió en Andalucía.

Las primeras universitarias españolas abrieron brecha para encaminar a otras mujeres a los estudios superiores, no sin polémica en la comunidad universitaria y ciertos círculos políticos y culturales que miraban con recelo que las mujeres accedieran a ello.

Era la carrera de medicina la de elección entre las universitarias en los primeros diez años del siglo XX en España. En 1909, las de medicina constituían el 50\% del total de mujeres que cursaban estudios universitarios, aunque esta proporción disminuyó bastante hasta los cincuenta, empezando a ascender de nuevo hasta 1975. Desde los años treinta a los ochenta

\footnotetext{
${ }^{3}$ La autora comenta y traduce del catalán al castellano el artículo de PÉREZ PRIÓ, E. Les tres primeres metgesses catalanes. D'Aci d'Allá. Vol. IV (1919), n. ${ }^{\circ} 12$, pp. 1118.

${ }^{4}$ Archivo de la Universidad de Cádiz (AUCA). Libro registro de títulos de la Facultad de Medicina en Cádiz, 1885-1918, L-279 FM, p. 70, n. ${ }^{\circ}$ 47; Expediente personal de Antonia Monreal Andrés, 1889-1895, C-159 (1)-6 FM.

${ }^{5}$ AUCA. Libro registro de títulos de la Facultad de Medicina en Cádiz, 1885-1918, L-279 FM, p. 60, n. 31.

${ }^{6}$ AUCA. Expediente personal de María del Mar Terrones Villanueva, 1910-1915, C-249 (2)-17 FM.

DOI del artículo:

https://doi.org/10.25267/Cuad investig fondos arch UCA.2021.i3.05 
fue creciendo gradualmente el número de médicas que ejercían en Andalucía, alcanzando su máxima expresión a partir de los setenta. Se produjo un aumento del nivel de feminización de la profesión, un 15\% de médicas en Andalucía en la década de los ochenta. (Ortiz Gómez 1985-1986).

El ejercicio profesional de las médicas ha mantenido un nivel alto de especialización. Las mujeres se han dedicado más a las especialidades que históricamente se han considerado aptas a su competencia: Pediatría, Ginecología, Oftalmología, Análisis Clínicos, Hematología, Microbiología y Anestesia. Con el paso de los años y hasta la actualidad, el espectro de especialidades elegidas por mujeres ha ido aumentando, siendo más igualitaria entre ambos sexos.

\section{Médicas de la Facultad de Medicina de CÁdiZ}

Las mujeres que aquí se relatan son estudiantes que realizaron la carrera de Medicina en la Facultad de Cádiz (en adelante FMC). Algunas no concluyeron los estudios o se trasladaron en algún curso a otra universidad española donde terminaron, pero todas las que se nombran pasaron por nuestra Facultad, se matricularon y realizaron algunos cursos.

A partir de la licenciatura ha habido mucha dificultad para encontrar datos sobre qué les aconteció después, pues algunas se trasladaron a otras ciudades andaluzas y españolas antes de comenzar su recorrido profesional. Teniendo en cuenta que la colegiación era obligatoria entre 1898 y 1902 y voluntaria entre 1903 y 1904, desde estas fechas hasta 1922 ninguna lo hizo, por ello podrían haber ejercido sin estar colegiadas o colegiarse allí donde ejercieron. La colegiación obligatoria para el ejercicio profesional fue a partir de 1917 y la primera médica colegiada en Cádiz consta en el año 1941 (Colegio Oficial de Médicos de Cádiz).

\subsection{SIGLOXIX}

\section{ANTONIA MONREAL Y ANDRÉS ${ }^{7}$}

Fue la primera universitaria y médica andaluza. Nace en Cádiz en 1872. Grado de bachiller (28 de septiembre de 1889) con calificación de sobresaliente, nota que repetiría en la mayoría de las asignaturas de medicina. Inició la carrera el curso 1889-1890 y concluyó en 1896 en la Facultad de Medicina de Cádiz. El examen de grado de licenciatura lo realizó en febrero de 1896 con la calificación de sobresaliente y obtuvo el título de licenciatura el 7 de marzo de 1896 (figura 1). A partir de aquí nada sabemos que esté debidamente documentado, si ejerció, dónde y su especialidad. (Flecha García 1996).

\footnotetext{
${ }^{7}$ AUCA. Libro registro de títulos de la Facultad de Medicina en Cádiz, 1885-1918, L-279 FM, p. 70, n. ${ }^{\circ}$ 47; Expediente personal de Antonia Monreal Andrés, 1889-1895, C-159 (1)-6 FM.

DOI del artículo: 
Figura 1. Grado de licenciada en 1896 de la primera médica de Cádiz y Andalucía, siglo XIX

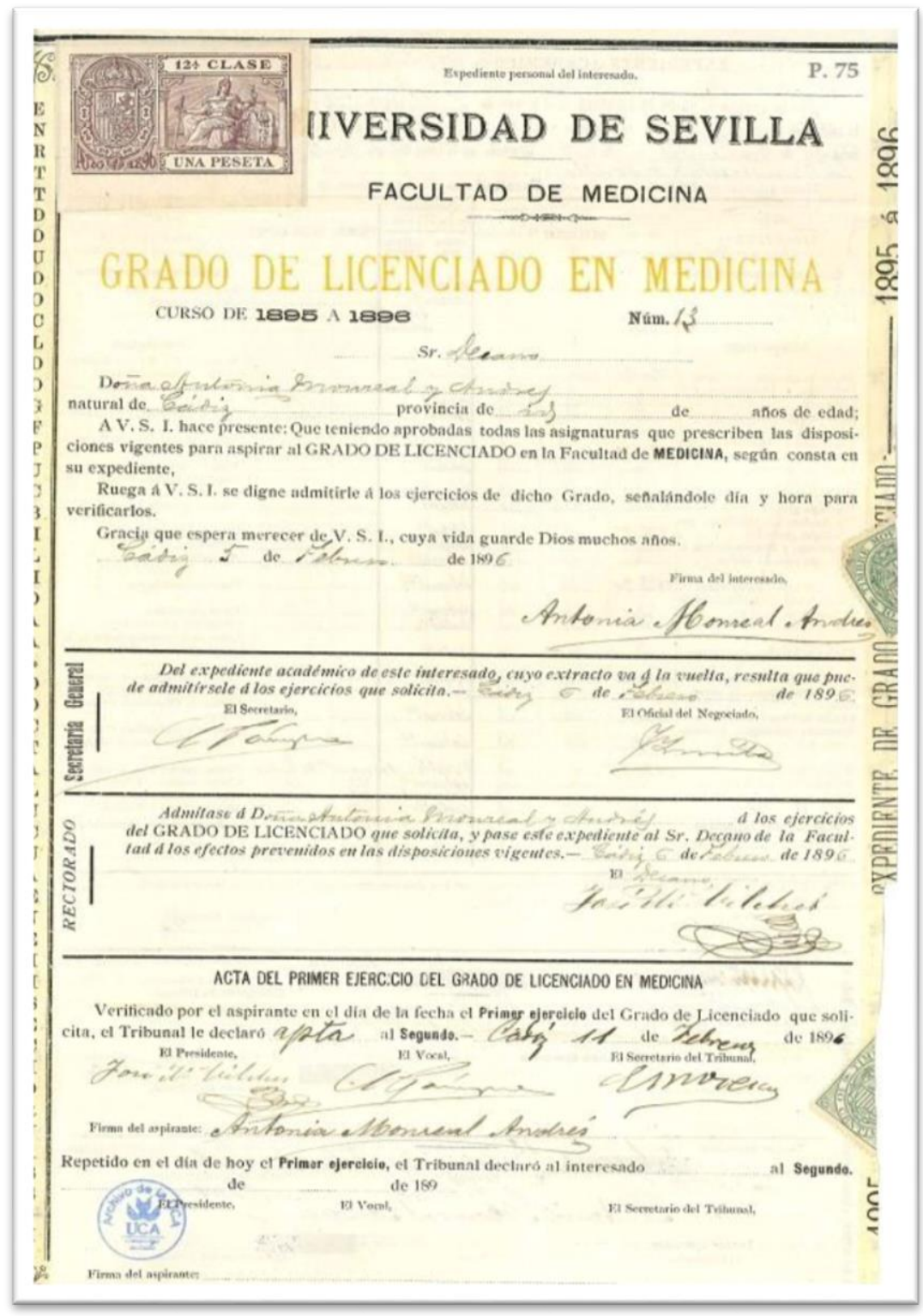

Fuente: Archivo de la Universidad de Cádiz (AUCA). Expediente personal de Antonia Monreal Andrés, 1889-1895, C-159 (1)-6 FM

\section{MARÍA ASUnCión MENÉNDEZ DE LUARCA Y DíAZ ${ }^{8}$}

Natural de Guanabacoa, La Habana (Cuba, 1858). Fue la primera mujer que se matriculó en la Facultad de Farmacia de La Habana en 1883, realizó en un solo año el examen de grado y varias asignaturas del doctorado obteniendo el título de licenciada en el curso 1887-1888 con la calificación de sobresaliente, graduándose así en el período entre 1880-1898, último período universitario bajo control español en la isla (Marchante Castellano y Merchán González 2010). Doctora en Medicina por la Universidad de Atlanta (Georgia, USA) en marzo

${ }^{8}$ AUCA. Expediente personal de María Asunción Menéndez de Luarca Díaz, 1883-1889, C-159 (1)-1 FM; Libro registro de títulos de la Facultad de Medicina en Cádiz, 1885-1918, L-279 FM, p. 60, n. 31. 
de 1893, convalidó la licenciatura en la Facultad de Medicina de Cádiz, aprobó el grado de licenciatura en octubre de 1894 con sobresaliente y obtuvo su título de licenciada el 11 de diciembre de 1894. En su expediente del Archivo de la Universidad de Cádiz (en adelante AUCA) consta que estuvo matriculándose de asignaturas en la Facultad de Medicina de Cádiz hasta 1892 y el 30 de agosto de este mismo año solicita al Decano del Colegio de Medicina de Cádiz todos los documentos acreditativos porque tiene que regresar a Cuba. Posteriormente y tras pasar por Atlanta en la fecha comentada, volvería a Cádiz donde obtendría el título de licenciada.

\section{LORETO ALCÁZAR Y LÓPEZ ${ }^{9}$}

Natural de Tarancón, Cuenca (1843). Realizó el bachiller en Sevilla. En su expediente consta la solicitud para iniciar la carrera en el curso 1868-1869, siendo admitida y apareciendo el pago de los derechos de matrícula, no obstante, no aparece expediente académico alguno y sí una hojilla donde se escribe subrayado «Traslado a la Central» por lo que suponemos se trasladó a la Universidad Central de Madrid para realizar los siguientes cursos de la carrera.

\subsection{SIGLOXX}

\section{María del Mar TerRones Villanueva ${ }^{10}$}

María del Mar Terrones nació en Orce (Granada, 1892). Su infancia y juventud transcurren en San Fernando y Cádiz porque su padre Manuel Terrones del Pino estuvo destinado en San Fernando, era profesor de Instrucción Pública, hombre muy comprometido con la enseñanza pública y de reconocido prestigio en la ciudad.

En 1909 ya había concluido el bachiller con calificación de sobresaliente y Premio Extraordinario de bachiller en Ciencias, ingresando en la Escuela Normal de Maestras. Consigue el Premio Extraordinario como Maestra de primera enseñanza en la Escuela Normal de Magisterio de Madrid y posteriormente el Título de Honor como Maestra Superior también con Premio Extraordinario.

En 1910 era alumna de la FMC con el curso preparatorio, iniciando la carrera en 1911. En 1914 oposita a una plaza de alumna interna, obteniendo el número uno y siendo asignada a las áreas Quirúrgica y Ginecología en el Hospital Clínico. Obtuvo sobresaliente y matrícula de honor en todas las asignaturas de la carrera. Se licenció en 1915 con la calificación de sobresaliente. Posteriormente, marcha a Madrid para la realización del doctorado.

Los datos biográficos de María del Mar Terrones que comento están extraídos del interesante libro El pensamiento audaz tiende su vuelo (2011), de la catedrática de Lengua y Literatura Española y escritora Cristina Ruiz Guerrero, que ha querido en esta obra reseñar aquellas mujeres que a finales del XIX y principios del XX destacaron en el periodismo gaditano como articulistas y colaboradoras literarias, entre ellas la estudiante de medicina María del Mar Terrones Villanueva.

${ }^{9}$ AUCA. Expediente personal de Loreto Alcázar López, 1866-1870, C-60-15 FM.

${ }^{10}$ AUCA. Expediente personal de María del Mar Terrones Villanueva, 1910-1915, C-249 (2)-17 FM.

DOI del artículo:

https://doi.org/10.25267/Cuad investig fondos arch UCA.2021.i3.05 
Mientras realiza la carrera de Medicina, $\mathrm{M}^{\mathrm{a}}$ del Mar da clases de enfermería y farmacia de forma voluntaria a las alumnas del Centro Protector de Obreras Gaditanas, convencida de lo importante de la educación y formación de las mujeres. Solicita que las alumnas hagan prácticas en el Hospital de Mujeres, consiguiendo el apoyo del presidente de la Unión Médica el Dr. Bartolomé Gómez Plana y del Dr. Federico Rubio, y que recibieran un diploma acreditativo que formalizara estos estudios y les permitiera conseguir un trabajo remunerado.

Se dedicó al periodismo durante sus años de juventud, fue colaboradora en algunos diarios, apareciendo sus artículos en la prensa de Cádiz y San Fernando. Destaca el artículo que escribe en el Diario de Cádiz denominado Mi protesta (diciembre 1911), contraria a las declaraciones de la periodista y escritora Rosario de Acuña (La chanza de la universidad, Diario El Progreso, Barcelona, 22 de noviembre de 1911), en el que arremete contra los estudiantes de la Universidad de Madrid en un tono más que despectivo porque insultaron y acosaron a unas estudiantes extranjeras. $\mathrm{M}^{\mathrm{a}}$ del Mar se une a las protestas de los estudiantes a nivel nacional dado el malestar creado por ese artículo. El periódico ABC de Madrid, de 2 de diciembre de 1910 recoge:

En provincias, el Diario de Cádiz publica un artículo de la Srta. María del Mar Terrones, alumna de la Facultad de Medicina de Cádiz, protestando contra el injurioso escrito de Rosario de Acuña. «Protesto — dice la joven escritora gaditana- por el atropello que han sufrido todos los estudiantes, mis compañeros; las mujeres españolas, mis hermanas y la Patria, mi madre».

La revista ilustrada Diana le dedicó una portada (figura 2) con el siguiente texto: «Srta. María del Mar Terrones Villanueva. Maestra de Primera Enseñanza; alumna oficial de la Facultad de Medicina de Cádiz y Socio de Honor del Centro Escolar Gaditano» (Diana AIIIn. ${ }^{\circ}$ 91-12 diciembre de 1911). Al finalizar el año 1911, es galardonada en el Certamen de la Asociación de la Prensa de Cádiz, por un trabajo sobre el lema Ganarás el pan haciéndose eco el Diario de Cádiz. María del Mar es propuesta para entrar como socia de mérito en la Asociación de la Prensa de Cádiz, tendría unos 19 años (Acta n. ${ }^{\circ} 13$ de la Junta extraordinaria, 29 de diciembre de 1911).

En su afán de compromiso y promoción de la educación femenina, $\mathrm{M}^{\mathrm{a}}$ del Mar se acerca a la Institución Teresiana. Tras fundarse las primeras residencias universitarias femeninas en Madrid, M ${ }^{\text {a }}$ del Mar Terrones se relaciona con mujeres tan importantes como María de Maeztu, Victoria Kent, María de Echarri y otras. Ella misma fundó y dirigió un centro en Cádiz, La Academia e Internado, inaugurándose el 5 de septiembre de 1914, que por motivos económicos y personales fue insostenible, abandona la dirección y se cierra (Ruiz Guerrero 2011).

Desconocemos si llegó a ejercer la medicina y si continuó su actividad periodística. Vivió en Madrid y su nombre apareció en ocasiones en ecos de sociedad del periódico ABC de la Capital. 
Figura 2. María del Mar Terrones Villanueva, primera médica de Andalucía del siglo XX

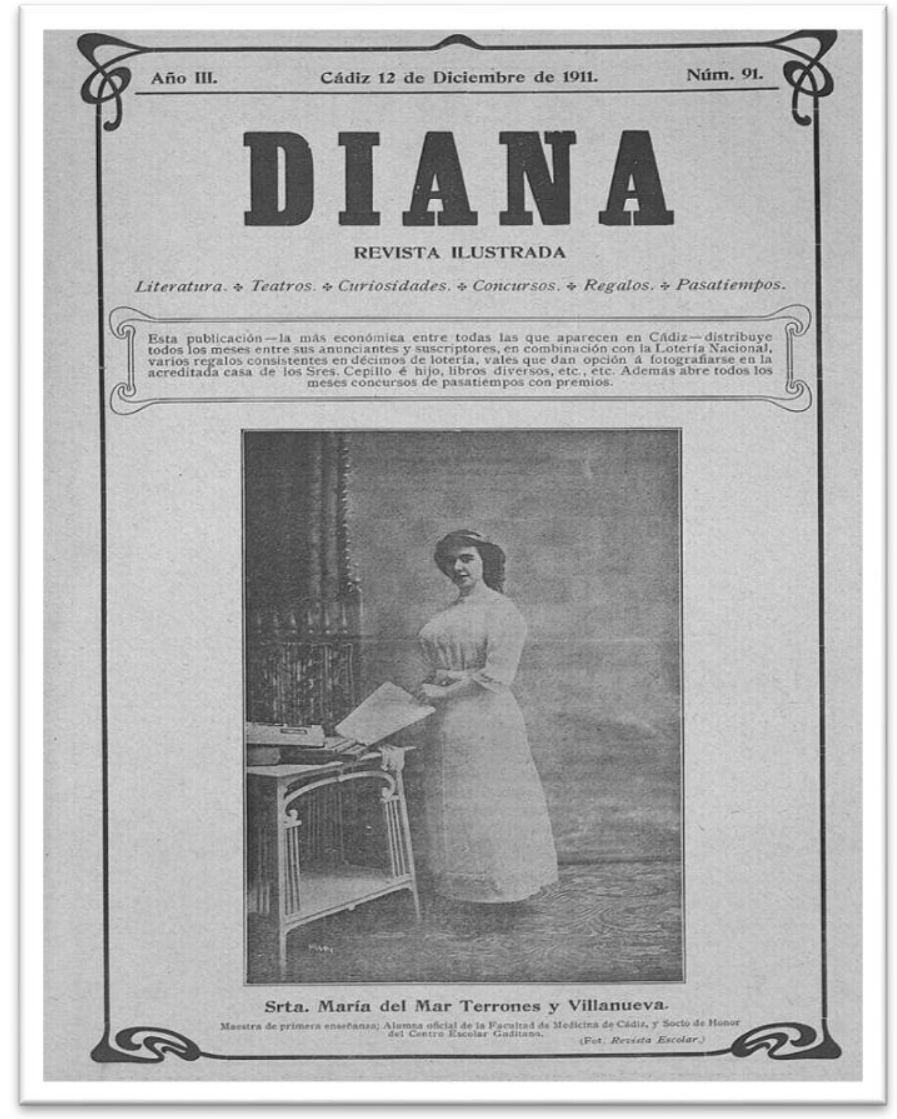

Fuente: www.prensahistorica.mcu.es/es/publicaciones/numeros_por_mes

\section{FRANCISCA MEDINA VERDEJA ${ }^{11}$}

Natural de Málaga (1891), inicia los estudios de maestra en esta ciudad y los termina en la Escuela Normal de Cádiz. Comenzó la carrera en la FMC el curso 1912-13, licenciándose el año 1918 con muy buenas calificaciones. En su expediente del AUCA, constan las papeletas de las asignaturas de todos los cursos, pero no un único expediente académico. Marchó a Madrid en 1918 para el doctorado. Fue una de las primeras médicas que ejercieron en Andalucía. Tenía un «consultorio para señoras» donde constaba ser especialista en enfermedades de la mujer y niños.

\section{MAgDalena Cirera Y PAUlA ${ }^{12}$}

Natural de San Pedro de Rindervilles (Barcelona), obtuvo el grado de bachiller en Valencia (1915). Trasladó su expediente a la Facultad de Medicina de Cádiz en 1917 iniciando la carrera de medicina, enseñanza no oficial, en el mismo año. En el curso 1920-21 se matricula del último curso, pero no hay expediente académico completo ni fecha de licenciatura.

\footnotetext{
${ }^{11}$ AUCA. Expediente personal de Francisca Medina Verdeja, 1912-1919, C-236 (4)-6 FM.

${ }^{12}$ AUCA. Expediente personal de Magdalena Cirera Paula, 1917-1921, C-233 (3)-35 FM.

DOI del artículo: 


\section{JOSEFA DE SARRIÁ GUERRERO ${ }^{13}$}

Nace en San Fernando (Cádiz, 1901). Obtuvo el título de bachiller en Cádiz en 1918 con la calificación de sobresaliente e inicia la carrera de Medicina el curso 1921-22. En su expediente académico no constan los siguientes cursos realizados, pero en el Libro de Títulos del AUCA se comprueba el título de licenciada expedido en fecha de 15 de noviembre de 1944.

\section{MERCEDES CHACÓN GONZÁLEZ ${ }^{14}$}

Natural de Torrenueva (Ciudad Real). Nació entre 1904-1905 (no consta entre sus escasos documentos). Grado de bachiller en el instituto de Ciudad Real en 1919, otro dato aporta que realizó el bachiller en Cádiz obteniendo el título en 1923. Muy probablemente inició la carrera en el curso 1923-1924, pues consta la matrícula del primer curso el 25 de octubre 1923, pero ningún otro dato en su expediente sobre la conclusión de la carrera ni de licenciatura.

\section{AdELAIDA NAVARRo PATIÑO ${ }^{15}$}

Natural de Orgaz (Toledo, 1907). Inició la carrera de Medicina en Cádiz en 1924, concluyéndola en 1931 con sobresaliente, trasladando el expediente a la Universidad de Madrid en 1932 para la realización del doctorado. Fue la única mujer licenciada en la promoción de 1931 y la primera mujer médico de la FMC en la II República.

En el año 1934 se encontraba en Río Tinto (Huelva) donde comenzó a ejercer de Pediatra, trasladándose en 1941 a Cádiz, siendo la primera mujer colegiada en Cádiz en 1941 (según el Colegio Oficial de Médicos de Cádiz, en adelante COMCADIZ).

En el Boletín Oficial del Estado (BOE) de 10 de julio de 1942, Orden de 8 de julio de 1942, por la que se aprueba el concurso de Antigüedad o de Prelación en el Escalafón del Cuerpo Médico de Asistencia Pública Domiciliaria (Convocatoria 1941), aparece Adelaida Navarro Patiño como propietaria de una plaza ( $5^{\mathrm{a}}$ categoría, municipio de Casasbuenas, Toledo).

\section{LORENZA BAENA SAINZ ${ }^{16}$}

Natural de Zafra (Badajoz, 1910). Grado de bachiller realizado en Badajoz y expedido en Sevilla en 1927. Inició la carrera de Medicina en el curso 1926-1927 concluyéndola en 1933 con excelentes calificaciones. Se traslada a la Universidad de Madrid para el doctorado en 1934 y desconocemos dónde ejerció la profesión.

\section{FERMINA GOÑ LÓPEZ ${ }^{17}$}

Natural de Navalmoral de la Mata (Cáceres). En su expediente académico consta el título de bachiller expedido en Madrid en 1927, iniciando la carrera el mismo año, trasladándose

\footnotetext{
13 AUCA. Expediente personal de Josefa de Sarriá Guerrero, 1917-1923, C-282 (2)-22 FM; Libro registro de títulos de la Facultad de Medicina en Cádiz, 1935-1983, L-335 FM.

${ }^{14}$ AUCA. Expediente personal de Mercedes Chacón González, 1905-1915, C-205 (2)-14 FM.

${ }^{15}$ AUCA. Expediente personal de Adelaida Navarro Patiño, 1924-1940, C-219 (1)-2 FM.

16 AUCA. Expediente personal de Lorenza Baena Sainz, 1927-1934, C-301 (2)-42 FM.

${ }^{17}$ AUCA. Expediente personal de Fermina Goñi López, 1929-1929, C-294 (3)-51 FM.
}

DOI del artículo: 
posteriormente a la Facultad de Cádiz donde continuó hasta segundo curso y de nuevo trasladó su expediente a la Universidad de Madrid, Facultad de Odontología, en junio de 1929. Sin otros datos sobre la conclusión de la carrera ni de ejercicio profesional.

\section{Rosario ViLla VALENZUELA ${ }^{18}$}

Nace en Lucena (Córdoba, 1910). Título de bachiller expedido en Sevilla. Comenzó la carrera de Medicina en nuestra facultad el curso de 1927-1928 y en el último curso, 1932-33 solicitó traslado del expediente a la Facultad de Medicina de Madrid donde concluyó la carrera. Las calificaciones de los 5 cursos realizados en la FMC fueron de sobresaliente. Realiza la tesis doctoral en La Universidad Central de Madrid, dirigida por Gregorio Marañón y Posadillo, cuyo título fue: La personalidad sexual y las glándulas endocrinas extra gonadales. Especialista en Pediatría.

\section{EMILIA ANAYA MAYORAL ${ }^{19}$}

Natural de Cádiz (1900). Tras realizar el bachiller en Cádiz inició los estudios de Medicina en la facultad el curso 1933-34 por libre. En su expediente consta que se traslada a la facultad de Sevilla en el otoño de 1934, y de nuevo vuelve a la FMC ya en cursos oficiales desde 1941 hasta 1944 que concluyó la carrera y realizó la reválida de licenciatura. El título fue expedido en marzo de 1946, año en que se colegió en nuestro Colegio Oficial de Médicos de Cádiz, permaneciendo colegiada hasta que se trasladó a Barcelona en 1948, colegiándose allí y ese mismo año vuelve a Cádiz, permaneciendo colegiada en nuestra provincia hasta su fallecimiento en 1984. Consta como especialista en Medicina Homeopática (COMCADIZ).

\section{JOSEFA DE LOS REYES DÍEZ ${ }^{20}$}

Josefa de Los Reyes Díez nació en Cádiz en 1919. Hija de un médico, Manuel de los Reyes García, y de una maestra, Josefa Díez de Prado. Cursó el bachillerato en Cádiz, en el Instituto Columela (título de grado de bachiller expedido en 1937). En plena contienda bélica de la Guerra Civil (1936-1939) estudió Magisterio en la Escuela Normal que permaneció abierta durante la guerra y en la que estudiaron bastantes mujeres bachilleras.

Prestó colaboración desinteresada en el Colegio del Patrocinio de San José de Extramuros de Cádiz desde 1936 a 1938, estando encargada de la clase de párvulos al objeto de que no quedasen sin apoyo escolar los 90 niños de la barriada durante el tiempo que las Hijas de la Caridad, residentes y maestras habituales de dicho colegio, prestaban asistencia en Hospitales Militares.

Colaboró de voluntaria en la Sección de Química del Laboratorio del Hospital Militar de Cádiz en el año 1939. Fue militante de la Sección Femenina de Cádiz desde septiembre de 1936, desempeñando el cargo de Regidora Local de Prensa y Propaganda hasta 1938 y prestó servicios en la Delegación de Auxilio Social, Frentes y Hospitales.

\footnotetext{
${ }_{18}$ AUCA. Expediente personal de Rosario Villa Valenzuela, 1927-1932, C-300 (1)-11 FM.

${ }^{19}$ AUCA. Expediente personal de Emilia Anaya Mayoral, 1933-1946, C-303 (3)-46 FM.

20 AUCA. Libro registro de títulos de la Facultad de Medicina en Cádiz, 1935-1983, L-335 FM, n. ${ }^{\circ} 2160$; Expediente personal de Josefa Covadonga de los Reyes Díez, 1939-1965, C-344 (2)-32 FM.

DOI del artículo: 
Inició la carrera de Medicina en la Facultad de Cádiz el curso 1939-1940, concluyendo en el curso de 1944-1945 con sobresaliente en casi todas las asignaturas, siendo expedido el título de licenciada en julio de 1945. Fue nombrada Alumna Interna Numeraria por oposición en la Facultad de Medicina adscrita a Medicina Legal (1942).

Realizó la especialidad de Puericultura y Pediatría y el doctorado en Madrid. Inició su ejercicio profesional en el Hospital de Mora de Cádiz, encontrándose allí de guardia el día de la Explosión (1947). Años después saca la oposición de Pediatra del Seguro Obligatorio de Enfermedad (S.O.E.). (Fuente de datos: familiar).

Fue la primera mujer médico que ejerció en Jerez de la Frontera, de donde era su padre, también médico y gitano, inicialmente en las dependencias del S.O.E. de aquel entonces y posteriormente en el Ambulatorio de San Dionisio. Ejerció la medicina en los Hogares y Guarderías de Auxilio Social. Médica con gran vocación, comprendió las necesidades de todo tipo por las que pasaban la ciudad de Jerez y sus gentes entre los años 40-50. Si no tenían seguridad social los atendía igualmente, y en algunos casos les facilitaba alimentos, medicamentos e incluso algo de dinero. Con ascendencia gitana, ayudó a este colectivo en Jerez, donde era muy querida. Fue una persona inteligente y generosa, solía comentar que la independencia de la mujer sólo podía venir de la mano de la educación y la formación. (Fuente de datos: familiar).

Falleció en 1982 a los 63 años en Jerez de la Frontera. El Ayuntamiento de Jerez en reconocimiento a su trayectoria profesional, a su labor social y ayuda al pueblo de dicha ciudad, le dedicó una calle con su nombre y años después le dio nombre a un Instituto de Enseñanza Media (Vidal Jiménez 2004).

\section{AURORA MiLLÁN MiLLÁN ${ }^{21}$}

Natural de Algeciras (1923). Consta en su expediente académico que inició la carrera de Medicina el curso 1943-44, concluyendo en 1950. Ese mismo año se matricula de los cursos del doctorado y aprueba la reválida de licenciatura (30/6/50). Fue especialista en Análisis Clínico (título expedido en 1972).

\section{MARÍA LUISA DE LA FUENTE HARO ${ }^{22}$}

Nace en Sevilla en 1930. Realizó el bachiller en el instituto Murillo (1947). Parece que inició la carrera de Medicina en el curso 1947-48, matriculándose sólo de algunas asignaturas. En su expediente el último curso reseñado fue 1951-52 con asignaturas de tercero. Realizó varios cursos por libre (de 1952 a 1954) hasta concluir la carrera en 1955. Consta en los libros de títulos del AUCA la solicitud del título de licenciada ese mismo año (expedido definitivamente en 1957).

${ }^{21}$ AUCA. Expediente personal de Aurora Millán Millán, 1943-1973, C-415 (3)-65 FM.

22 AUCA. Libro registro de títulos de la Facultad de Medicina en Cádiz, 1935-1983, L-335 FM, n. ${ }^{\circ}$ 5591; Expediente personal de María Luisa de la Fuente Haro, 1952-1957, C-361 (1)-7 FM.

DOI del artículo: 


\section{NATIVIDAD CUENCA GARCÍA ${ }^{23}$}

Nació en Madrid en 1931. Realizó el bachiller en La Laguna (Tenerife). Inició la carrera el curso 1949-50, enseñanza oficial, y concluyó en 1955, obteniendo muy buenas calificaciones. No constan otros datos.

\section{CONCEPCIÓN TAPIA SABINA ${ }^{24}$}

Natural de Santa Cruz de Tenerife (1931). Inició la carrera el curso de 1949-50, concluyéndola por libre el curso 1954-55. Realizó la reválida de licenciatura en 1956 con la calificación de sobresaliente y consta en su expediente la matrícula a los cursos del doctorado. El título de licenciada fue expedido en Santa Cruz de Tenerife en 1957. Especialista en Pediatría y Puericultura, ejerció en esa isla.

\section{CASTORA LARA SEGURA ${ }^{25}$}

Natural de Badajoz (1932). Inició curso oficial en 1949-50 y concluyó por libre el curso 1954-55. Título de licenciada en 1962. Ningún otro dato en su expediente académico.

\section{AnTONia Gamboa LaGo ${ }^{26}$}

Nació en Cádiz en 1933. Título de bachiller expedido en Sevilla en 1952. Inició la carrera de Medicina el curso 1951-1952 y se licenció en el curso de 1958 (título de licenciada expedido en 1959). En primero le fue concedida la Beca de José Antonio Primo de Rivera, dotada con 750 pesetas mensuales, que disfrutó durante toda la carrera. Entre sus documentos aparece un ejercicio de Reválida fechado el 1 de Julio 1956 con la calificación de sobresaliente y un Premio Extraordinario del curso 1957-1958. Ocupó una plaza de Médico Interno en la Cátedra de Fisiología de la que solicita su renuncia en 1959. Solicitó realizar la tesis doctoral en la Facultad de Medicina de Cádiz bajo la dirección del profesor José Mira Gutiérrez, siendo el título del trabajo propuesto Estudio histológico, histoquímico y ultraestructural de helmintos y parásitos humanos que lee en 1974. Fue especialista en Pediatría.

\section{MARÍA ViCTORIA BOTO ESCAMILLA ${ }^{27}$}

Natural de Madrid (1933). Inició el curso oficial de Medicina en 1951-52 y concluyó la carrera por libre el curso 1956-57. Reválida de licenciatura con la calificación de Apta en 1957 y en el curso siguiente consta la matrícula de los cursos del doctorado. Realizó la tesis doctoral en Cádiz, dirigida por el profesor Antonio López Rodríguez, con lectura el 7 de julio de 1959 y calificación de Sobresaliente. Constan dos títulos: Estudio e interpretación de la malformación cardíaca del embrión humano de $22 \mathrm{~mm}$ y otro Contribución al estudio de las arterias pulmonares. No consta especialidad ni si ejerció en Cádiz.

\footnotetext{
${ }^{23}$ AUCA. Expediente personal de Natividad Cuenca García, 1949-1956, C-420 (1)-30 FM.

${ }^{24}$ AUCA. Expediente personal de Concepción Tapia Sabina, 1947-1955, C-424 (5)-92 FM.

${ }^{25}$ AUCA. Expediente personal de Castora Lara Segura, 1949-1962, C-446 (2)-23 FM.

${ }^{26}$ AUCA. Expediente personal de María Antonia Gamboa Lago, 1951-1977, C-340 (1)-13 FM.

${ }^{27}$ AUCA. Expediente personal de María Victoria Boto Escamilla, 1951-1959, C-427 (3)-43 FM.
}

DOI del artículo: 
IGNACIA SALVANS CASAS ${ }^{28}$

Natural de Manresa (Barcelona, 1904). Realizó la carrera de Medicina en Barcelona, iniciándola en el curso 1921-22 y concluyó en 1928 con excelentes notas. El grado de licenciatura también sobresaliente. Se matriculó de los cursos del doctorado en el curso 194849 en la Facultad de Cádiz y leyó la tesis doctoral, dirigida por el profesor Diego Ferrer Fernández de la Riva, catedrático de histología, el 7 de julio de 1958 con la clasificación de sobresaliente cum laude.

\section{RosARIo POZUELO MiLláN ${ }^{29}$}

En su documentación no consta expediente académico, pero sí el certificado de profesora adjunta interina en la cátedra de Anatomía Descriptiva y Topográfica (de 1956-1958). Consta expedido título de licenciada en junio de 1955. Especialidad: Pediatría.

\section{MARÍA DEl CARMEN MORA DE LOS RÍOS ${ }^{30}$}

No consta en su carpeta el expediente académico ni datos de filiación, sólo certificados del nombramiento de profesora ayudante de clases prácticas de Anatomía Descriptiva y Topográfica en 1971, cesando un año después. Según el libro de títulos, concluyó la carrera en 1955.

\section{AMPARO CASTRO MAYOR ${ }^{31}$}

Natural de Fermoselle (Zamora, 1930). Inició la carrera de Medicina en Salamanca el curso 1949-50, trasladando expediente a la Facultad de Cádiz tras concluir tercero en 1952. Continuó la carrera, enseñanza oficial, durante dos cursos y terminó por libre en 1957. Solicitud del título de licenciatura en 1958.

\section{María MANUEla Guerrero Oliva ${ }^{32}$}

Natural de Cádiz (1932). Inició la carrera, enseñanza oficial, en el curso 1950-51 y concluyó en 1957 por libre. Reválida de licenciatura Apto en el primer ejercicio y Sobresaliente en el segundo. Matriculada en los cursos del doctorado entre 1957-58. Solicitó beca de los laboratorios MADE-SA a postgraduados para realizar la especialidad de Pediatría y Puericultura (21/8/58). Retira el título de licenciada un familiar el 11 de junio de 1959 por encontrarse ella trabajando en un hospital de Brooklyn (Nueva York).

\footnotetext{
${ }^{28}$ AUCA. Expediente personal de Ignacia Salvans Casas, 1957-1958, C-435 (3)-50 FM.

${ }^{29}$ AUCA. Libro registro de títulos de la Facultad de Medicina en Cádiz, 1935-1983, L-335 FM; Expediente personal administrativo de Rosario Pozuelo Millán, Ayudante de Clases Prácticas de Anatomía Descriptiva, 1956-1958, C-727-12 FM.

30 AUCA. Libro registro de títulos de la Facultad de Medicina en Cádiz, 1935-1983, L-335 FM; Expediente personal administrativo de María del Carmen Mora De los Ríos, Ayudante de Clases Prácticas de Anatomía Descriptiva y Topográfica, 1971-1972, C-725-22 FM.

${ }^{31}$ AUCA. Archivo de la Universidad de Cádiz (AUCA). Expediente personal de Amparo Castro Mayor, $1952-$ 1958, C-435 (3)-33 FM.

32 AUCA. Expediente personal de Manuela Guerrero Oliva, 1949- 1978, C-430 (2)-29 FM.

DOI del artículo: 


\section{MARÍA Luisa DerQui García 33}

Natural de Puerto Real, Cádiz (1934). Inició la carrera el año 1953-54, enseñanza oficial y concluyó en 1960 por libre. Reválida de licenciatura: aprobado (1961). Título de licenciatura expedido en 1960. Consta en su expediente la realización de los cursos del doctorado. Especialidad Pediatría (título de 1984).

\section{CARMEN ARANíbar SOTElo ${ }^{34}$}

Natural de Cádiz (1929). Realizó el curso preparatorio entre 1952-53 en la FMC y este mismo año se le concedió la beca Alejandro Salazar por el Sindicato de Estudiantes Universitarios (SEU). Inició la carrera, enseñanza oficial, el curso 1953-54, concluyéndola el curso 1958-59. Reválida de licenciatura en 1959, sobresaliente. Título de licenciada expedido en 1960. Se realizó traslado de expediente desde Facultad de Cádiz a La Laguna (Tenerife) porque residía allí. No consta especialidad y suponemos ejerció la profesión en la isla.

\section{AlbA MARINA ROMERO ${ }^{35}$}

Natural de Boconó, Trujillo (Venezuela, 1929). Consta en su expediente que le fue convalidado el título de bachiller en el Instituto Lope de Vega de Madrid en 1955. No queda claro en su expediente si la carrera la inicia fuera de España, lo cierto es que la Facultad de Medicina de Madrid le convalidan los cursos desde $1^{\circ}$ a $5^{\circ}$, y parte de $6^{\circ}$ y $7^{\circ}$ se matricula en enseñanza oficial en dicha facultad. Posteriormente traslada expediente a la Universidad de Sevilla, Facultad de Medicina de Cádiz, el curso 1955-1956 donde concluye. Título de licenciada de 1956 que se remite al Consulado de Venezuela en Madrid. Ningún otro dato de especialidad y ejercicio profesional.

Por la Ley orgánica 3/2018 de 5 de diciembre de Protección de Datos, no se pueden consultar en el AUCA los expedientes académicos de las estudiantes y médicas a partir de determinado año.

Revisamos por ello los libros de títulos del AUCA, donde constan el año de licenciatura, la fecha de solicitud del título de licenciado y la fecha de expedición de dicho título y otros libros de registro interno de matrículas (del AUCA) con el objetivo de conocer el número aproximado de médicas licenciadas. Los datos encontrados por períodos de años desde 1859 a 1969, se exponen en la tabla I.

A partir de 1970, el número de mujeres matriculadas en la carrera va paulatinamente in crescendo hasta alcanzar en la década de los 80 cifras similares a los estudiantes masculinos e incluso, superarlos en número en la década de los 90 (ej. promoción 1991-1997: 84 mujeres y 61 varones).

\footnotetext{
${ }^{33}$ AUCA. Expediente personal de María Luisa Derqui García, 1953-1984, C-440 (3)-33 FM.

${ }^{34}$ AUCA. Expediente personal de Carmen Aranibar Sotelo, 1952- 1972, C-432 (1)-9 FM.

${ }^{35}$ AUCA. Expediente personal de Alba Marina Romero, 1945-1955, C-422 (5)-99 FM.
}

DOI del artículo: 
Tabla I. Licenciadas de la Facultad de Medicina de Cádiz, período 1859-1969

PERIODO DE TIEMPO NÚMERO DE MUJERES LICENCIADAS

\begin{tabular}{lr}
\hline $1859-1899$ (40 años) & 2 licenciadas \\
\hline $1900-1939$ (40 años) & 6 licenciadas \\
\hline $1940-1949$ (10 años) & 4 licenciadas \\
\hline $1950-1959$ (10 años) & 12 licenciadas \\
\hline $1960-1969$ (10 años) & 40 licenciadas
\end{tabular}

Fuente: Elaboración propia. Archivo de la Universidad de Cádiz ${ }^{36}$

Podrían ser más las mujeres médicas licenciadas en nuestra FMC en este período del siglo $\mathrm{XX}$, cuyos expedientes no se encuentran en el AUCA y que no ha sido posible consultar. También se han revisado cajas entre cuyos documentos no se encontraban los expedientes académicos, pero sí documentos acreditativos de toma de posesión de plazas de profesoras adjuntas interinas y de clases prácticas, sin poder asegurar que fueron alumnas de la Facultad de Medicina de Cádiz.

Hemos encontrado estudiantes que no terminaron la carrera en Cádiz, trasladando expediente a otra ciudad y por tanto no se registran los títulos de licenciadas, pero fueron estudiantes de nuestra facultad. Revisamos un buen número de orlas (del AUCA y privadas) y algunas médicas no se fotografiaron para tal fin, por ello, aunque nos ha servido de información, no constituye una fuente fidedigna.

\section{REPERCUSIÓN DEL ACCESO DE LA MUJER A LA PROFESIÓN MÉDICA EN LA ESPAÑA DEL SIGLO XIX Y PRINCIPIOS DEL SIGLO XX}

Como hemos referido hasta ahora, el tema de la formación académica de la mujer y concretamente en las facultades de medicina, suscitó polémicas, artículos periodísticos y divergencias entre compañeros facultativos. Incluso los Reyes, a través de sus Órdenes Reales, también tuvieron que tomar cartas en el asunto de permitir o no que las mujeres pudieran acceder a la formación de Enseñanza Media y Superior.

En esta sección nos centraremos en describir la repercusión que tuvo en España el acceso de la mujer a la profesión médica a finales del siglo XIX y en Cádiz, a través de la mirada y opinión de los colegas médicos.

La médica valenciana María del Carmen Álvarez Ricart realiza un excelente trabajo de investigación histórica en su libro La mujer como profesional de la medicina en la España del siglo XIX, centrado en la mujer sanitaria y médica, cuya fuente fundamental fue una revisión del periodismo médico español de dicho siglo, recogiendo un total de 118 artículos desde 1968 a 1984, tomando como base el Index Medicus, el Índice Médico Español y el catálogo de

\footnotetext{
${ }^{36}$ Archivo de la Universidad de Cádiz (AUCA). Libro primero Registro de entrega de Títulos, 1852-1866, L-592 FM; Libro registro de títulos de la Facultad de Medicina en Cádiz, 1866-1884, L-297 FM; Libro registro de títulos de la Facultad de Medicina en Cádiz, 1885-1918, L-279 FM; Libro registro de títulos de la Facultad de Medicina en Cádiz, 1935-1983, L-335 FM.

DOI del artículo: 
Historia de la Medicina del instituto Wellcome, entre otros. La problemática que enfrentaron las estudiantes de Medicina y las médicas del XIX, fueron las mismas que se encontraron en esta profesión bien avanzado el siglo XX.

Durante el siglo XIX la incorporación de la mujer a los estudios de Medicina empezó a verse en Europa. Ante estos hechos, parte del ambiente médico español reacciona desfavorablemente, lo que se recoge en algunos escritos:

Frase de La España Médica de 1864 (p. 633):

... De manera que invadido nuestro terreno por ellas y conservando su influencia sobre el corazón del hombre, no extrañaremos ver en breve el triunfo de las mujeres. Ellas en la tribuna, en las ciencias, en el gobierno, ellos hilando, espumando la olla y lavando pañales. ¡Qué aberraciones!

O esta otra del Siglo Médico, 1866 (p. 479):

... En el Seminario de Wesleyad (Inglaterra) se han graduado de doctoras siete señoritas que pronunciaron sus discursos correspondientes, y como allí se han graduado podrán graduarse en España, si las dejan...

O esta del Progreso Médico, 1872:

... Una señorita catalana acaba de obtener el título de Bachillera en artes y se prepara a estudiar medicina en la Universidad de Barcelona. Cuando hay hombres que tanto se afeminan, no extrañamos que haya hembras que tanto se varonicen...

Estas frases de artículos escritos en la prensa médica española del siglo XIX son un ejemplo de todas las recogidas en su libro (Álvarez Ricart 1988).

El escritor y médico Arthur Conan Doyle (1859-1930), en su cuento Los doctores de Hoyland perteneciente al libro Cuentos de Médicos y Militares, refiere como el Dr. Ripley se encuentra por primera vez con una «mujer médico» y queda sorprendido, sublevándose ante semejante idea, reflexionando por qué no, pero a su vez tiene la sensación de que se había concurrido en una blasfemia. Esto muestra el conflicto naciente en el siglo XIX en Inglaterra (extrapolable a toda Europa) ante el hecho de que algunas mujeres empezaban a acceder a la profesión médica provocando desconcierto en sus colegas (Conan Doyle 1894).

Hubo teorías y experimentos científicos por toda Europa y Norte América, así como opiniones de médicos, menospreciando las facultades físicas e intelectuales de la mujer, lo que provocó un sesgo ideológico negativo sobre el sexo femenino que por desgracia se mantuvo en el tiempo hasta fechas relativamente recientes.

En el siglo XIX fueron pocas las mujeres españolas que acudieron a las universidades, no sin dificultades, pero fueron valientes y decididas, y abrieron camino a nuevas estudiantes y profesionales. La incorporación de las mujeres a la carrera de Medicina se produce en las dos últimas décadas del siglo XIX en un número muy reducido, desatando la polémica sobre «si éramos o no aptas para estudiar y ejercer Medicina»o si «las mujeres tienen otras tareas que realizar que no los estudios y mucho menos la de ser médicos» (Álvarez Ricart 1969).

Las opiniones de los colegas médicos estaban divididas acerca de la conveniencia o no de que las mujeres se dedicasen a ejercer la Medicina, siendo la mayoría contrarias, lo que pudo influir sobre la medida tomada en 1888 según la cual las matriculadas precisaban de un permiso académico especial que no se le exigía al varón y que estuvo vigente hasta 1910. 
La sociedad en época del 1874 a 1931 (Restauración Borbónica) pensaba que a cada sexo le correspondían diferentes cualidades y funciones, existían diferencias fisiológicas y también culturales entre ambos sexos, y afirmaban que en el hombre predominaban la razón y la libertad, mientras que en la mujer prima su sensibilidad y la trascendente labor de ser el núcleo de la familia (Folguera Crespo 1997).

«La mujer en el matrimonio encuentra su realización plena, ha de tener una buena educación moral que le permita entender al esposo y cierto grado de instrucción para educar a sus hijos». En estos términos escribe la articulista y escritora María Pilar Sinués y Navarro (Zaragoza 1835-Madrid 1893) en su libro El ángel del hogar. Estudios morales acerca de la mujer (1857), de gran éxito, que se reeditó durante treinta años. Todo desde una visión católica y conservadora. Pero ella no vivió como prodigó y enseñó a las mujeres en sus escritos, se separó, no tuvo hijos, vivió con independencia económica y libremente inmersa en una importante actividad intelectual (Biblioteca Nacional de España).

En Cádiz destacamos las opiniones y artículos de un insigne médico gaditano, Juan José Cambas Gallego (1833-1877), licenciado en la FMC en 1856, joven con grandes inquietudes, viajó con 23 años a Paris y posteriormente se traslada a Madrid para realizar el doctorado (1868) y ejercer la profesión. Escribe en periódicos médicos como El Especialista y Anales de la Medicina, Cirugía y Farmacia, participa en la redacción de la Enciclopedia de Ciencias Médicas y funda y dirige el periódico El Progreso Médico. Promovió el asociacionismo médico y formó a muchas mujeres para ejercer de matronas. Era un hombre progresista y simpatizó con la Revolución de 1868, pero al escribir sus opiniones sobre la «mujer médico» deja claro que se muestra contrario al ejercicio de la medicina por la mujer. Estamos seguros de que la opinión de Cambas era la de la mayoría de sus colegas de la época, temerosos ante el hecho de que la mujer avance en la jerarquía social e intelectual hasta llegar al nivel del hombre. Este párrafo lo refleja claramente:

Creemos a la mujer capaz del trabajo intelectual, hasta cierto punto, en armonía siempre con su carácter, en general, superficial, ligero, poco dado a profundas meditaciones, y a las largas horas de vigilia junto a libros de ciencias. La juzgamos incapaz del ejercicio de la profesión médica, aunque sobre esto hacemos una distinción. Si por mujer se entiende la hembra humana que puede disparar una carabina, incendiar con petróleo un edificio, echar su hijo a la cuna, batirse con un gendarme, defender una barricada, fumar Virginia, beber cognac y blasfemar como un dragón, estamos de acuerdo en que sirve también para amputar un brazo, hacer una ovariotomía y sondar uretra del hombre. Pero si llamamos mujer a la criatura débil, cariñosa, apacible, de exquisita sensibilidad [...] hija cariñosa, esposa honrada y virtuosa madre [...] y palidece ante una gota de sangre, llora junto al que sufre [...], esa mujer, decimos, no puede ni aún soñar en la práctica de nuestra profesión capaz de abatir el ánimo de muchos hombres y de agotar las fuerzas de Hércules (Herrera Rodríguez 2000, p. 95).

Investigando sobre doctorandos del siglo XIX en nuestra Facultad, entre los años 18691875 en pleno Sexenio Democrático, llama la atención lo repetitivo del título de las tesis, literalmente: Educación física y moral que debe darse a la mujer con relación a los deberes que la naturaleza le ha impuesto. 
Hemos encontrado exactamente 10 tesis con dicho título: 6 en el AUCA $^{37}$ y las de Francisco Meléndez Herrera, Juan José Cambas Gallego, Diego Costa Grijalva y la tesis de 1865 con el mismo título, de Miguel Moreno Martínez (Herrera Rodríguez 1987) ${ }^{38}$.

En otras tesis, el tema de la educación (instrucción moral) de la mujer reaparece, como en la de Antonio Francisco Pérez y Carmona $(1871)^{39}$, De la mujer considerada como centro de la familia, ¿cumple su misión en el cristianismo o en las demás religiones?, o en la tesis de Enrique Bauzano López $(1869)^{40}$, Influencia de la vida monástica en la salud de la mujer, o la de Juan Toruño León $(1874)^{41}$, Es más noble, más delicado y más justo que el hombre eduque, que no que el hombre avasalle a la mujer y la de Luis Gonzaga Moreno Sínigo (1875) Reglas higiénicas que deben seguirse en la educación de la mujer.

Catorce tesis doctorales de médicos de la FMC que opinan sobre la educación moral que han de recibir las mujeres para que puedan seguir al esposo y educar a sus hijos dentro de los cánones cristianos, contemplándose una mínima instrucción para este empeño, pero para nada una formación superior o académica. Por el contrario, en estos trabajos recogemos unas frases que nos dejan claro cuáles eran sus opiniones al respecto: «... No se trata de formar bachilleras atolondradas y célebres literatas, sino de que su educación la consagre a la sublime poesía de la familia...». «... No somos partidarios de la mujer llamada beata, de la gazmoña, ni de la marisabidilla; sino de la mujer sólidamente instruida, capaz de conocer siempre la verdad y el bien, de estimarlos y enseñarlos a sus hijos...».

Sería incompleto este trabajo si no comentásemos algunos datos. Primero, que no hay referencia de que ninguna de las primeras estudiantes de medicina en España tuviera que marcharse a otro país a cursar estos estudios, como sí ocurrió en otros lugares. Segundo, que hubo profesores y médicos que se mostraron proclives a la entrada de mujeres en la universidad y en las facultades de medicina, no sin a su vez ser criticados por los colegas que pensaban lo contrario. Profesores de renombre y prestigio reconocido ayudaron a que estas primeras mujeres pudieran acudir a clases, recelosas como estaban a los condicionamientos sociales. Entre ellos destacan algunos nombres en el XIX en la Universidad de Barcelona: A. Fórmica Corsí, J. Ginés Partagás, N. Carbós y J. Letamendi y en la primera década del siglo XX un ejemplo ilustre, Santiago Ramón y Cajal, maestro (1907-08) y admirador de su alumna Manuela Solís y Claras (licenciada en Valencia, 1889). Y tercero, ya a finales del XIX comienzan a oírse célebres voces femeninas defendiendo el derecho de la mujer a acceder a la educación en todos sus grados, tales fueron Concepción Arenal (1820-1893), Emilia Pardo Bazán (1851-1921), Clara Campoamor (1888-1972), Victoria Kent (1891-1987) y otras.

\footnotetext{
${ }^{37}$ AUCA. Expediente personal de José Celestino López Jiménez, 1840-1850, C-2 (1)-1 FM; Expediente personal de Domingo Beca Morales, 1843-1850, C-110 (2)-9 FM; Expediente personal de José Enrique Castro Lorca, 1850-1860, C-47 (2)-15 FM; Expediente personal de Manuel Ruiz Vargas Páramo, 1850-1860, C-47 (2)-20 FM; Expediente personal de Juan Ruiz-Cabal Rodríguez, 1863-1869, C-47 (1)-10 FM; Expediente personal de Bartolomé Belmonte Cardenas, 1865-1872, C-45 (2)-14 FM.

${ }^{38}$ Estos trabajos fueron catalogados previamente en la tesis doctoral de Francisco Herrera Rodríguez (1987) con otro objetivo, la investigación científica de la FMC a través de sus tesis doctorales en el siglo XIX y nos llama la atención que muchos doctorandos eligieran el mismo tema, más bien sociológico y humanístico que científico.

${ }^{39}$ AUCA. Expediente personal de Francisco Pérez Carmona, 1855-1860, C-83 (1)-2 FM.

${ }^{40}$ AUCA. Expediente personal de Enrique Bauzano López, 1855-1860, C-85 (1)-2 FM.

${ }^{41}$ AUCA. Expediente personal de Juan Toruño León, 1842-1847, C-25 (1)-4 FM.
}

DOI del artículo:

https://doi.org/10.25267/Cuad investig fondos arch UCA.2021.i3.05 
Para terminar, nuestra antigua Facultad de Medicina de Cádiz, a pesar de no estar incluida inicialmente en una universidad propia, ya que pertenecía al Distrito de la Universidad de Sevilla, gozó siempre de un gran prestigio desde el punto de vista científico y tradición histórica, por ello atrajo alumnado de otras universidades y acogió a las primeras universitarias de Cádiz para realizar estudios superiores. Hoy en día las circunstancias han cambiado para las mujeres que constituyen un colectivo profesional igualitario y destacado en la profesión médica.

\section{AGRADECIMIENTOS}

A María Clemencia, María del Rosario, Berta, María José y María de los Dolores, del Archivo de la Universidad de Cádiz, incansables y eficientes colaboradoras. Al profesor Francisco Herrera por sus trabajos, siempre de gran ayuda. Al Excelentísimo Colegio Oficial de Médicos de Cádiz por su aportación bibliográfica. A la Biblioteca de la Universidad de Cádiz por su colaboración. A la familia Arcas de los Reyes por la amable y generosa información sobre su madre, Josefa de los Reyes Díez.

\section{REFERENCIAS BIBLIOGRÁFICAS}

Álvarez RICART, M.C., 1969. Algunas opiniones sobre el estudio de la medicina por la mujer durante el siglo XIX en España. Asclepio, vol. 21, pp. 49-54. ISSN 0210-4466.

Álvarez RicART, M.C., 1988. La mujer como profesional de la medicina en la España del siglo XIX. Barcelona: Anthropos. ISBN 84-7658-106-8.

Biblioteca Nacional de EsPaÑA, 2016. Escritores en la BNE: María del Pilar Sinués (1835-1893). [en línea] Disponible en: https://escritores.bne.es/web/authors/maria-delpilar-sinues-1835-1893/ [Consulta 8 septiembre 2020].

Conan DoYle, A., 1894. The Doctors of Hoyland. [en línea] Disponible en: https://www.arthur-conan-doyle.com/index.php?title=The_Doctors_of_Hoyland [Consulta 12 agosto 2020].

Corpas Mauleón, J.R., 1994. La enfermedad y el arte de curar en el Camino de Santiago entre los siglos X y XVI. [Santiago de Compostela]: Dirección Xeral de Promoción do Camiño de Santiago. ISBN 84-453-1145-X.

Bernis CARro, C. y CÁMARA GonZÁlez, C., 1982. La mujer y la medicina. En: M.A. DurÁN, ed. Liberación y utopía. Madrid: Akal, pp. 205-230. ISBN 84-7339-584-0.

ESEVERRI CHAVERRI, C., 1984. Historia de la enfermería española e hispanoamericana. Barcelona: Salvat. ISBN 84-345-2404-X.

FleCHA GARCÍA, C., 1996. Las primeras universitarias en España: 1872-1910. Madrid: Narcea. ISBN 84-277-1159-X.]

Folguera CRESPO, P., 1997. Revolución y Restauración: la emergencia de los primeros ideales emancipadores (1868-1931). En: E. GARRIDO GONZÁLEZ, ed. Historia de las mujeres en España. Madrid: Síntesis, pp. 451-492. ISBN 84-7738-525-4. 
Herrera RodríGuez, F., 2000. Gavilla de médicos gaditanos. Cádiz: Quorum Libros. pp 8997. ISBN 84-88599-30-7.

HERRERA RodríGUeZ, F., 1987. La investigación científica en la Facultad de Medicina de Cádiz a través de las tesis doctorales producidas en la misma en el siglo XIX. Tesis doctoral inédita. Cádiz: Universidad de Cádiz.

Marchante Castellano, P. y Merchán González, F., 2010. Estudiantes y graduados de farmacia en la Real Universidad de La Habana en el período 1880-1898: las primeras farmacéuticas cubanas. Revista Cubana de Farmacia, vol. 45 (1), pp.111-124. ISSN 0034-7515.

MCDONALD, L. ed., 2008. The collected works of Florence Nightingale, Volume 11: Florence Nightingale's Suggestions for thought. Waterloo, Ont.: Wilfrid Laurier University Press. ISBN 978-0-88920-465-2.

ORTIZ GóMEZ, T., 1985-1986. La mujer como profesional de la medicina en la España contemporánea: el caso de Andalucía, 1898-1981. Dynamis: Acta Hispanica ad Medicinae Scientiarumque Historiam Illustrandam, vol. 5-6, pp. 343-366. ISSN 02119536.

Ruiz Guerrero, C., 2011. El pensamiento audaz tiende su vuelo: pioneras del periodismo en Cádiz. Cádiz: Quorum Libros. ISBN 978-84-92581-41-2.

SAnZ Artibucilla, J.M., 1970. Vida documental de la Sierva de Dios Madre María Rafols: fundadora de la Congregación de Hermanas de la Caridad de Santa Ana, de Zaragoza. Zaragoza: El noticiero.

VIDAL JIMÉNEZ, M., 2004. Avenidas, calles, plazas e instituciones rotuladas con nombres de médicos en Cádiz y su provincia. [Cádiz]: Excmo. Colegio Oficial de Médicos de la Provincia de Cádiz.

\section{FUENTES DOCUMENTALES}

Archivo de la Universidad de Cádiz (AUCA). Expediente personal administrativo de María del Carmen Mora De los Ríos, Ayudante de Clases Prácticas de Anatomía Descriptiva y Topográfica, 1971-1972, C-725-22 FM.

Archivo de la Universidad de Cádiz (AUCA). Expediente personal administrativo de Rosario Pozuelo Millán, Ayudante de Clases Prácticas de Anatomía Descriptiva, 1956-1958, C727-12 FM.

Archivo de la Universidad de Cádiz (AUCA). Expediente personal de Adelaida Navarro Patiño, 1924-1940, C-219 (1)-2 FM.

Archivo de la Universidad de Cádiz (AUCA). Expediente personal de Alba Marina Romero, 1945-1955, C-422 (5)-99 FM.

Archivo de la Universidad de Cádiz (AUCA). Expediente personal de Amparo Castro Mayor, 1952-1958, C-435 (3)-33 FM.

Archivo de la Universidad de Cádiz (AUCA). Expediente personal de Antonia Monreal Andrés, 1889-1895, C-159 (1)-6 FM.

DOI del artículo:

https://doi.org/10.25267/Cuad investig fondos arch UCA.2021.i3.05 
Archivo de la Universidad de Cádiz (AUCA). Expediente personal de Aurora Millán Millán, 1943-1973, C-415 (3)-65 FM.

Archivo de la Universidad de Cádiz (AUCA). Expediente personal de Bartolomé Belmonte Cardenas, 1865-1872, C-45 (2)-14 FM.

Archivo de la Universidad de Cádiz (AUCA). Expediente personal de Carmen Aranibar Sotelo, 1952-1972, C-432 (1)-9 FM.

Archivo de la Universidad de Cádiz (AUCA). Expediente personal de Castora Lara Segura, 1949-1962, C-446 (2)-23 FM.

Archivo de la Universidad de Cádiz (AUCA). Expediente personal de Concepción Tapia Sabina, 1947-1955, C-424 (5)-92 FM.

Archivo de la Universidad de Cádiz (AUCA). Expediente personal de Domingo Beca Morales, 1843-1850, C-110 (2)-9 FM.

Archivo de la Universidad de Cádiz (AUCA). Expediente personal de Emilia Anaya Mayoral, 1933-1946, C-303 (3)-46 FM.

Archivo de la Universidad de Cádiz (AUCA). Expediente personal de Enrique Bauzano López, 1855-1860, C-85 (1)-2 FM.

Archivo de la Universidad de Cádiz (AUCA). Expediente personal de Fermina Goñi López, 1929-1929, C-294 (3)-51 FM.

Archivo de la Universidad de Cádiz (AUCA). Expediente personal de Francisca Medina Verdeja, 1912-1919, C-236 (4)-6 FM.

Archivo de la Universidad de Cádiz (AUCA). Expediente personal de Francisco Pérez Carmona, 1855-1860, C-83 (1)-2 FM.

Archivo de la Universidad de Cádiz (AUCA). Expediente personal de Ignacia Salvans Casas, 1957-1958, C-435 (3)-50 FM.

Archivo de la Universidad de Cádiz (AUCA). Expediente personal de José Celestino López Jiménez, 1840-1850, C-2 (1)-1 FM.

Archivo de la Universidad de Cádiz (AUCA). Expediente personal de José Enrique Castro Lorca, 1850-1860, C-47 (2)-15 FM.

Archivo de la Universidad de Cádiz (AUCA). Expediente personal de Josefa Covadonga de los Reyes Díez, 1939-1965, C-344 (2)-32 FM.

Archivo de la Universidad de Cádiz (AUCA). Expediente personal de Josefa de Sarriá Guerrero, 1917-1923, C-282 (2)-22 FM.

Archivo de la Universidad de Cádiz (AUCA). Expediente personal de Juan Ruiz-Cabal Rodríguez, 1863-1869, C-47 (1)-10 FM.

Archivo de la Universidad de Cádiz (AUCA). Expediente personal de Juan Toruño León, 1842-1847, C-25 (1)-4 FM.

Archivo de la Universidad de Cádiz (AUCA). Expediente personal de Lorenza Baena Sainz, 1927-1934, C-301 (2)-42 FM.

Archivo de la Universidad de Cádiz (AUCA). Expediente personal de Loreto Alcázar López, 1866-1870, C-60-15 FM.

Archivo de la Universidad de Cádiz (AUCA). Expediente personal de Magdalena Cirera Paula, 1917-1921, C-233 (3)-35 FM. 
Archivo de la Universidad de Cádiz (AUCA). Expediente personal de Manuel Ruiz Vargas Páramo, 1850-1860, C-47 (2)-20 FM.

Archivo de la Universidad de Cádiz (AUCA). Expediente personal de Manuela Guerrero Oliva, 1949-1978, C-430 (2)-29 FM.

Archivo de la Universidad de Cádiz (AUCA). Expediente personal de María Antonia Gamboa Lago, 1951-1977, C-340 (1)-13 FM.

Archivo de la Universidad de Cádiz (AUCA). Expediente personal de María Asunción Menéndez de Luarca Díaz, 1883-1889, C-159 (1)-1 FM.

Archivo de la Universidad de Cádiz (AUCA). Expediente personal de María del Mar Terrones Villanueva, 1910-1915, C-249 (2)-17 FM.

Archivo de la Universidad de Cádiz (AUCA). Expediente personal de María Luisa de la Fuente Haro, 1952-1957, C-361 (1)-7 FM.

Archivo de la Universidad de Cádiz (AUCA). Expediente personal de María Luisa Derqui García, 1953-1984, C-440 (3)-33 FM.

Archivo de la Universidad de Cádiz (AUCA). Expediente personal de María Victoria Boto Escamilla, 1951-1959, C-427 (3)-43 FM.

Archivo de la Universidad de Cádiz (AUCA). Expediente personal de Mercedes Chacón González, 1905-1915, C-205 (2)-14 FM.

Archivo de la Universidad de Cádiz (AUCA). Expediente personal de Natividad Cuenca García, 1949-1956, C-420 (1)-30 FM.

Archivo de la Universidad de Cádiz (AUCA). Expediente personal de Rosario Villa Valenzuela, 1927-1932, C-300 (1)-11 FM.

Archivo de la Universidad de Cádiz (AUCA). Libro primero Registro de entrega de Títulos, 1852-1866, L-592 FM.

Archivo de la Universidad de Cádiz (AUCA). Libro registro de títulos de la Facultad de Medicina en Cádiz, 1866-1884, L-297 FM.

Archivo de la Universidad de Cádiz (AUCA). Libro registro de títulos de la Facultad de Medicina en Cádiz, 1885-1918, L-279 FM.

Archivo de la Universidad de Cádiz (AUCA). Libro registro de títulos de la Facultad de Medicina en Cádiz, 1935-1983, L-335 FM. 